\title{
Perihilar Intrahepatic Cholangiocarcinoma
}

National Cancer Institute

\section{Source}

National Cancer Institute. Perihilar Intrahepatic Cholangiocarcinoma. NCI Thesaurus.

Code C96804.

An intrahepatic cholangiocarcinoma that arises from the intrahepatic large bile ducts. 